\title{
AVALIAÇÃo DA EFICIÊNCIA DE TRÊS ÁGARES SELETIVOS NO ISOLAMENTO DE Listeria monocytogenes ${ }^{1}$
}

\author{
Denize Aparecida RODRIGUES ${ }^{2}$, Bernadette Dora Gombossi de Melo FRANCO²,
}

\author{
Mariza LANDGRAF², Maria Teresa DESTRO ${ }^{2, *}$
}

\begin{abstract}
RESUMO
A variedade de protocolos existentes para a pesquisa de Listeria sp em alimentos e outras amostras é muito grande, o que dificulta a escolha daquele que possa apresentar melhores resultados. Os protocolos recomendados nas metodologias tradicionais indicam vários caldos de pré-enriquecimento e enriquecimento seletivo, assim como meios de isolamento seletivo. O presente estudo teve por finalidade comparar a eficiência dos ágares cloreto de lítio-feniletanol-moxalactam (LPM), PALCAM (PAL) e do ágar hemolítico ceftazidimacloreto de litio (HCLA) no isolamento de L. monocytogenes a partir de diferentes tipos de amostras colhidas em uma linha de processamento de "nuggets" congelados de frango. Um total de 413 amostras foi examinado. As amostras foram primeiramente enriquecidas em caldo Half Fraser, seguido do enriquecimento em caldo BLEB. Aliquotas deste enriquecimento foram semeadas por esgotamento em placas contendo os meios LPM, PAL e HCLA. Colônias típicas foram selecionadas e submetidas à identificação bioquímica. O meio HCLA permitiu o isolamento de $L$. monocytogenes em $60,1 \%$ do total de amostras examinadas, enquanto PAL e LPM permitiram o isolamento em aproximadamente $47,9 \%$ das amostras. O desempenho do HCLA foi estatisticamente diferente dos demais meios (p< $0,05 \%$ para todos os tipos de amostras, exceto para as de manipuladores onde os 3 meios apresentaram desempenho semelhante. Os resultados obtidos com o HCLA foram superiores aos dos demais meios e seu uso, simultaneamente com o PAL, mostrou-se de grande utilidade. Palavras-chave: L. monocytogenes; isolamento; HCLA; PALCAM; LPM.
\end{abstract}

\section{SUMMARY}

EVALUATION OF THE EFFICIENCY OF THREE SELECTIVE AGARS FOR L. monocytogenes ISOLATION. There is a variety of protocols for Listeria spp detection in foods and other sources. Therefore, the decision on which method to be used becomes very difficult. Conventional isolation methodologies indicate different pre-enrichment and enrichment broths as well as different isolation media. The comparison between the efficiency of PALCAM (PAL), lithium chloride-phenylethanol-moxalactam (LPM) and haemolitic ceftazidimelithium chloride (HCLA) agars was carried out. A total of 413 samples from different sources, collected from a chicken nuggets processing plant, was pre-enriched in Half Fraser broth followed by enrichment in BLEB. They were streaked onto LPM, PAL and HCLA plates and typical colonies were submitted to biochemical identification. L. monocytogenes (Lm) was isolated from $60.1 \%$ of the samples when HCLA was used and from approximately $47.9 \%$ when PAL and LPM were considered. The difference between the efficiency of HCLA and the other two media was statistically significant $(p<0.05)$ for all samples but food handlers. For food handler samples all three media showed the same efficiency. The combined use of HCLA and PAL allowed the identification of the highest number of Lm positive samples indicating that these media can be a good choice.

Keywords: L. monocytogenes; isolation; HCLA; PALCAM; LPM.

\section{1 - INTRODUÇÃO}

A fim de atender a Legislação Brasileira e as exigências dos países importadores, os diversos segmentos da indústria alimentícia brasileira têm dado maior atenção à pesquisa de Listeria, tanto em seus produtos quanto no ambiente de produção.

A variedade de protocolos existentes para a pesquisa de Listeria e/ou L. monocytogenes em alimentos, ou em outras amostras de interesse para a indústria de alimentos, é muito grande tornando dificil a escolha daquele que possa apresentar melhores resultados.

A metodologia tradicional para isolamento de listerias está baseada no emprego de enriquecimento primário da amostra em meio liquido seletivo, seguido ou não de enriquecimento secundário também em meio seletivo. A seguir, aliquotas deste caldo de enriquecimento são semeadas em placas de ágares seletivos e, após in-

1. Recebido para publicação em 28/03/2002. Aceito para publicação em 28/05/2003 (000825).

2 Universidade de São Paulo - Depto. de Alimentos e Nutrição Experimental. Av. Prof. Lineu Prestes 580, Bl 14, CEP 05508-900, SP. E-mail. mtdestro@usp.br

* A quem a correspondência deve ser enviada. cubação, colônias suspeitas do microrganismo são identificadas através da avaliação de suas características.

Vários são os caldos de pré-enriquecimento e enriquecimento seletivos descritos na literatura, assim como meios de isolamento seletivo [2, 9, 11, 18, 21].

Os caldos de enriquecimento descritos apresentam composição básica muito semelhante, variando apenas a concentração e combinação dos agentes seletivos. Já os meios de isolamento de Listeria apresentam uma gama maior de variáveis. De maneira geral, exploram a resistência de Listeria a vários antibióticos como por exemplo, ácido nalidixico, polimixina B, moxalactam, cefotetan, cicloheximida, entre outros. Estes antibióticos são utilizados em conjunto com outros agentes seletivos tais como feniletanol, cloreto de lítio, acriflavina, anidrido glicínico e telurito de potássio.

Alguns meios possuem corantes que atuam como indicadores da utilização de carboidratos, como é o caso do ágar PALCAM [24], ou sistemas indicadores empregando esculina e íons ferrosos como no caso do próprio ágar PALCAM e do ágar Oxford [6]. Já com outros meios, como o ágar cloreto de litio feniletanol moxalactam [13] que não contém agentes diferenciais em sua formulação, há necessidade de se utilizar a iluminação obliqua 
transmitida (técnica de Henry) para que colônias suspeitas de Listeria possam ser identificadas.

A adição de sangue de diversas espécies animais aos meios de isolamento também tem sido proposta por diversos pesquisadores. A função do sangue seria não só tornar o meio mais rico, e assim auxiliar na recuperação do microrganismo, como também permitir a diferenciação entre cepas hemoliticas e não hemoliticas do gênero Listeria. Dentre estes meios, pode-se destacar os descritos por BLANCO et al. [4], por FORRET, DOREY [10] e o ágar hemolítico ceftazidima cloreto de lítio (HCLA) descrito por POYSKY et al. [21].

Recentemente, meios cromogênicos têm sido desenvolvidos e comercializados. Segundo os fabricantes alguns destes meios permitiriam a diferenciação entre Listeria monocytogenes e as outras espécies do gênero.

Dentre os meios seletivos mais empregados nos diversos países estão o ágar Oxford, o ágar Oxford modificado, ágar cloreto de litio feniletanol moxalactam (LPM) [17] e o ágar PALCAM.

Uma vez que são escassos em nosso meio estudos avaliando a eficiência de meios de cultura no isolamento de patógenos em amostras naturalmente contaminadas, este estudo teve por objetivo comparar a eficiência dos ágares PALCAM (PAL), cloreto de lítio feniletanol moxalactam (LPM) e do ágar hemolítico ceftazidima cloreto de lítio (HCLA) no isolamento de Listeria monocytogenes, a partir de diferentes tipos de amostras colhidas em uma linha de processamento de "nuggets" congelados de frango.

\section{2 - MATERIAL E MÉTODOS}

\section{1 - Material}

Um total de 413 amostras de diferentes tipos (ambiente, equipamentos, manipulador e produto) coletadas em uma linha de processamento de "nuggets" congelados de frango foi examinado para a presença de $L$. monocytogenes.

Amostras ambientais e de equipamentos foram colhidas com auxilio de zaragatoas estéreis que foram recolhidas em $25 \mathrm{~mL}$ de caldo Letheen (Difco). As amostras de mãos de manipuladores foram obtidas através da técnica de enxágüe de uma das mãos, conforme descrito por DESTRO et al. [7]. As amostras do alimento foram colhidas segundo recomendado por PAGOTTO et al. [19].

\section{2 - Métodos}

Porções de $25 \mathrm{~g}$ de alimento foram homogeneizadas, por $1 \mathrm{~min}$., com $225 \mathrm{~mL}$ de caldo Half-Fraser (HF - caldo Fraser adicionado de suplemento SR $166 \mathrm{M}$, ambos Oxoid) e foram incubadas a $30^{\circ} \mathrm{C}$ por $22 \mathrm{~h}$. Aliquotas de $0,1 \mathrm{~mL}$ foram transferidas para tubos contendo $9,9 \mathrm{~mL}$ de caldo tamponado para enriquecimento de Listeria (BLEB adicionado do suplemento SR141E, ambos Oxoid) e os tubos incubados por $22 \mathrm{~h}$ a $30^{\circ} \mathrm{C}$. Para as amostras de ambiente e equipamentos, a totalidade do conteúdo de cada tubo contendo as zaragatoas foi transferida para frascos contendo $225 \mathrm{~mL}$ de Caldo HF. Após homogeneização manual procedeu-se como descrito para as amostras de alimento. Dos $100 \mathrm{~mL}$ da solução de enxágüe das mãos dos manipuladores, $25 \mathrm{~mL}$ foram transferidos para $225 \mathrm{~mL}$ de $\mathrm{HF}$ e processados conforme descrito para as demais amostras.

Aliquotas de caldo BLEB foram semeadas por esgotamento em placas com ágar PAL (Oxoid), ágar LPM (Difco) e ágar HCLA preparado de acordo com POYSKY et al. [21]. As placas foram incubadas a $30^{\circ} \mathrm{C}$ por $24-$ 48h. De cada placa de PAL e de LPM foram selecionadas três colônias tipicas suspeitas de Listeria e da placa de HCLA foram selecionadas 2 colônias tipicas (com halo de hemólise) e 1 colônia atipica que foram purificadas em ágar soja tripticase adicionado de 0,6\% de extrato de levedura (TSA-YE, ambos Oxoid).

A seguir, as cepas foram submetidas à caracterização bioquímica empregando-se as provas de produção de catalase, de $\beta$-hemólise em ágar sangue de cavalo a $4 \%$, motilidade em ágar semi-sólido, produção de ácidos a partir de ramnose, dextrose, xilose e manitol. As cepas foram ainda submetidas ao teste API Listeria (bioMérrieux) para identificação complementar.

\section{3 - Análise estatística}

Para a comparação da eficiência dos meios de cultura avaliados empregou-se o teste de $\mathrm{c}^{2}$ de McNemar, a nivel de significância de 5\% [22].

\section{3 - RESULTADOS E DISCUSSÃO}

Segundo MOSSEL [18], 3 fatores podem influenciar o desempenho de um meio de cultura: os constituintes do alimento, a microbiota acompanhante e o efeito do processamento na viabilidade dos microrganismos pesquisados.

Para a escolha dos ágares seletivos empregados neste estudo, levou-se em consideração os agentes seletivos e os sistemas empregados na diferenciação das colônias para evitar o uso de meios com principios semelhantes. Assim, selecionou-se o LPM que tem como agente seletivo anidrido glicínico $(10 \mathrm{~g} / \mathrm{L})$, cloreto de lítio $(5 \mathrm{~g} / \mathrm{L})$ e moxalactam $(20 \mathrm{mg} / \mathrm{L})$. As colônias de Listeria apresentam cor verde-azulada e com aspecto de vidro moído quando examinadas sob luz obliquamente transmitida [13]. No PAL, emprega-se acriflavina (5mg/L), cloreto de litio $(15 \mathrm{~g} / \mathrm{L})$, ceftazidime $(20 \mathrm{mg} / \mathrm{L})$ e polimixina B (10mg/L) e tem como sistema indicador a hidrólise da esculina e a fermentação de manitol [24]. No HCLA tem-se como agentes seletivos, cloreto de litio $(7,5 \mathrm{~g} / \mathrm{L})$, colistina metano sulfonato (115.000 UI/L) e ceftazidime (20mg/L) e como sistema indicador a observação da produção de $\beta$-hemólise e de colônias com coloração verde azulada quando examinadas sob iluminação obliqua [20].

Na Figura 1 encontram-se as porcentagens de isolamento de $L$. monocytogenes para as diferentes amostras examinadas empregando-se os diferentes ágares. 


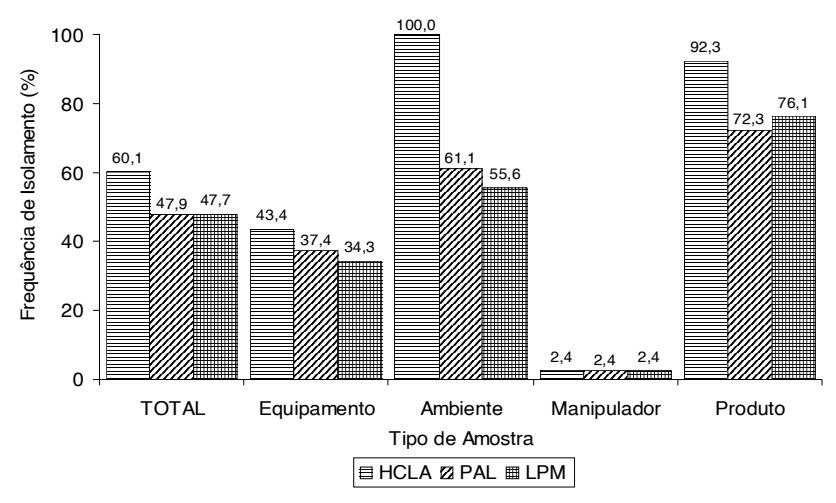

FIGURA 1 - Comparação de eficiência dos ágares seletivos PALCAM (PAL), Cloreto de lítio feniletanol moxalactam (LPM) e hemolítico ceftazidime cloreto de lítio (HCLA), no isolamento de L. monocytogenes a partir de diferentes tipos de amostras provenientes de uma linha de processamento de "nuggets" congelados de frango.

Pode-se observar, na Figura 1, que o meio HCLA permitiu o isolamento de L. monocytogenes em 60,1\% (248/413) do total de amostras examinadas enquanto que PAL e LPM permitiram o isolamento em $47,9 \%$ (198/413) e 47,8\% (197/413) das amostras respectivamente.

Quando se avalia o desempenho dos meios por tipo de amostra analisada verifica-se que o HCLA apresentou melhor desempenho que os demais meios tanto para amostras de equipamento, ambiente quanto de produto (Figura 1). Para manipuladores não houve diferença entre o desempenho dos três meios. A diferença entre os resultados obtidos com o meio HCLA e os meios LPM e PAL são estatisticamente significativas $(p<0,05)$, já entre os meios LPM e PAL não o são ( $p>0,05)$.

Semelhança entre o comportamento de PAL e LPM foi também observado por WARBURTON et al. [28]. Porém, VAN NETTEN et al. [25] verificaram ser o ágar PAL superior ao LPM. Estes mesmos autores notaram ainda que o ágar PAL apresentava melhor seletividade que o LPM, fato este também observado no presente trabalho.

Alguns pesquisadores relataram o bom desempenho do LPM no isolamento de Listeria monocytogenes [5, 15], enquanto que em outros estudos verificou-se o oposto [8, $26,29]$. O mesmo ocorre com o PAL, onde resultados diferentes foram obtidos por grupos diferentes [2, 16, 20, 27].

Numa avaliação realizada sobre meios de isolamento para Listeria monocytogenes foi acordado pelos membros da International Standard Organization (ISO) que o meio PAL apresentava ótimo desempenho mas que o meio Oxford, que permite a seleção de Listeria sp, poderia ser substituído por outro meio que permitisse a diferenciação de Listeria monocytogenes das demais listerias [2].

Para diversas amostras (26 amostras) só foi possivel isolar L. monocytogenes a partir do meio HCLA, sendo as mesmas negativas tanto no LPM quanto no PAL.

O HCLA apresentou seletividade semelhante ao PAL (dados não apresentados) porém, devido a adição de sobrecamada contendo sangue de cavalo é possivel separar L. monocytogenes de outras espécies, principalmente L. innocua, que normalmente ocorrem em alimentos e amostras ambientais.

A adição de sangue aos meios seletivos para isolamento de Listeria tem sido pesquisada já há algum tempo [3, 8, 10, 12, 23] porém, estudos com o HCLA ainda são raros. Quando descreveram o meio, em 1993, POYSKY et al. [21] compararam seu desempenho ao dos ágares Oxford e Oxford modificado e verificaram uma maior recuperação de L. monocytogenes quando empregaram o HCLA.

A utilização de mais de um meio de isolamento que empregue diferentes agentes seletivos e sistemas de identificação das colônias é de fundamental importância para aumentar a chance de isolamento do organismo alvo. Este procedimento é recomendado para bactérias cuja presença em alimentos, mesmo que em uma população pequena, pode expor o consumidor à situação de risco, como o caso de Salmonella [1] e L. monocytogenes.

Isto pode ser verificado na metodologia recomendada por HITCHINS [12] que sugere o emprego simultâneo dos ágares Oxford (OXA) e LPM ou OXA e PAL para a pesquisa de L. monocytogenes em alimentos. Já o Serviço de Inspeção e Segurança de Alimentos do Departamento de Agricultura dos EUA [24] sugere para o isolamento desta espécie bacteriana a partir de produtos cárneos e amostras ambientais, o emprego do agar Oxford modificado (MOX), seguido da purificação das colônias suspeitas em ágar com sobrecamada de sangue de cavalo ("horse blood overlay agar"). O emprego do HCLA concomitantemente ao MOX seria uma boa alternativa para diminuir o tempo gasto na análise quando se emprega a metodologia do USDA.

\section{4 - CONCLUSÕES}

Os resultados apresentados neste estudo indicam a superioridade do ágar HCLA sobre os demais meios de isolamento seletivos empregados, indicando que este pode ser uma boa escolha para a pesquisa de Listeria monocytogenes em alimentos, amostras ambientais ou de equipamentos, acompanhado, preferencialmente pelo PAL. A dificuldade de aquisição no mercado interno da colistina metanosulfonato, componente do HCLA, aliada ao seu preparo trabalhoso, podem interferir na popularização do seu emprego na pesquisa rotineira de $L$. monocytogenes.

\section{5 - REFERÊNCIAS BIBLIOGRÁFICAS}

[1] ANDREWS, W.H.; FLOWERS, R.S.; SIllikeR, J.; BAILEY, J.S. Salmonella. In: DOWNES, F.P.; ITO, K. Compendium of Methods for the Microbiological Examination of Foods. 4 ed. APHA, Washington, 2001. p. 357-380.

[2] ART, D.; ANDRE, P. Comparison of three selective isolation media for the detection of Listeria monocytogenes in foods. Zentralbl. Bakteriol., v. 275, n. 1, p. 79-84, 1991. 
[3] BEUMER, R.R. ISO11290-1, horizontal method for the detection of Listeria monocytogenes: change of isolation media. XIV International Symposium on Problems of Listeriosis, Mannheim, Alemanha, 13-16 maio de 2001. Book of Abstracts, p. 124.

[4] BLANCO, M.; FERNANDÉZ-GARAYZABAL, J.F.; DOMINGUEZ, L.; BRIONES, V.; VASQUEZ-BOLAND, J.A.; BLANCO, J.L.; GARCIA, J.A.; SUAREZ, G. A technique for the direct identification of haemolyticpathogenic listeria on selective plating media. Lett. Appl. Microbiol., v. 8, n. 4, p. 125-128, 1989.

[5] BUCHANAN, R.L.; STAHL, H.G.; BENCIVENGO, M.M.; CORRAL, F.D. Comparison of lithium chloride phenylethanol moxalactam and modified Vogel Johnson agars for detection of Listeria spp in retail-level meats, poultry and seafood. App1. Environ. Microbiol., v. 55, n. 3, p. 599-603, 1989.

[6] CURTIS, G.D.W.; MITCHELL, R.G.; KING, A.F.; GRIFFIN, E.J. A selective differential medium for the isolation of Listeria monocytogenes. Lett. Appl. Microbiol., v. 8, p. 95-98, 1989.

[7] DESTRO, M.T.; LEITÃO, M.F.F.; FARBER, J.M. Use of molecular typing methods to trace the dissemination of Listeria monocytogenes in a shrimp processing plant. Appl. Environ. Microbiol. v. 62, p. 705-711, 1996.

[8] DEstro, M.T.; SERRANO, A.M.; KABUKI, D.Y. Comparison of two plating media for the isolation of Listeria sp from some Brazilian dairy and meat products. Rev. Microbiol., v. 23, n. 4, p. 256-259, 1992.

[9] DOMINGUEZ, L.; FERNANDEZ-GARAYZABAL, J.F.; BLANCO, M.M.; BRIONES, V.; VAZQUEZ-BOLAND, J.A.; BLANCO, J.; SUAREZ, G. Overlay technique for direct detection and identification of haemolytic Listeria on selective plating medium. Comparison of five media. Z. Lebensm. Uters. Forsch., v. 191, n. 1, p. 1619, 1990.

[10] DONNELLY, C.W. Conventional methods to detect and isolate Listeria monocytogenes. In: RYSER, E.T.; MARTH, E.H. Listeria, liseriosis and food safety. Marcel Dekker, New York. 1999. p. 225-260.

[11] FORRET, J.; DOREY, F. Evaluation of a new culture culture medium to detect Listeria monocytogenes in raw milk. Sci. Aliments, v. 17, n. 2, p. 219-225, 1997.

[12] HITCHINS, A.D. Listeria monocytogenes. In: USA. Food and Drug administration. Bacteriological Analytical Manual online. Chapter 10. Aug 2002. Disponível em http://www.cfsan.fda.gov

[13] JOHANSSON, T. Enhaced detection and enumeration of Listeria monocytogenes from foodstuffs and foodprocessing environments. Int. J. Food Microbiol., v. 40, n. 1/2, p. 77-85, 1998.

[14] LEE, W.H.; McCLAIN, D. Improved Listeria monocytogenes selective agar. Appl. Environ. Microbiol., v. 53, n. 5 , p. 1215-1217, 1986.

[15] LOESSNER, M.J.; BELL, R.H.; JAY, J.M.; SHELEF, L.A. Comparison of seven plating media for enumeration of Listeria spp. Appl. Environ Microbiol., v. 54, n.12, p. 3003-3007, 1988.

[16] LUND, A.M.; ZOTTOLA, E.A.; PUSCH, D.J. Comparison of methods for isolation of Listeria from raw milk. J. Food Prot., v. 54, n. 8, p. 602-606, 1991.

[17] MCCLAIN, D.; LEE, W.H. FSIS method for the isolation and identification of Listeria monocytogenes from processed meat and poultry products. Laboratory Comunication n. 57, Beltsville: USDA-FSIS, 1989, 12p.
[18] MOSSEL, D.A.A. Introduction and perspective. Int. J. Food Microbiol., v. 2, p. 1-7, 1985.

[19] PAGOTTO, F.; DALEY, E.; FARBER, J.; WARBURTON, D. Isolation of Listeria monocytogenes from all food and environmental samples. In: Canada. Compendium of Analytical Methods. Vol. 3. Disponivel em http:// www.hc-sc.gc.ca/food-aliment/english/publications/ compendium/index.html

[20] Peters. M.; AmTsBerG, G.; Beckmann, G.T. The diagnosis of Listeria encephalitis in ruminants using cultural and immunohistological techniques. I. Comparison of different selective media and culture techniques for the detection of Listeria from ruminants brains. Zentralbl. Veterinarmed., Reihe B, v. 39, n. 6, p. 410-420, 1992.

[21] POYSKY, F.T.; PARANJPYE, R.N.; LASHBROOK, L.C.; PETERSON, M.E.; PELROY, G.A., EKLUND, M.W. Selective and differential medium for isolation of Listeria monocytogenes from foods. J. Food Prot., v. 56, n. 4, p. 326-329, 1993.

[22] RYSER, E.T.; DONNELly, C.W. Listeria. In: DOWNES, F.P.; ITO, K. (Eds.) Compendium of methods for the microbiological examination of foods. 4.ed. APHA, Washington, 2001. Cap. 36, p. 343-363.

[23] SIEGEL, S. Estatística não paramétrica (para ciências do comportamento). São Paulo: McGraw-Hill, 1975. $350 \mathrm{p}$.

[24] UNITED STATES DEPARTMENT OF AGRICULTURE. Food Safety Inspection Service. Isolation and identification of Listeria monocytogenes from red meat, poultry, eggs and environmental samples. In: Microbiology laboratory guidebook. Cap.8. rev. 29/04/ 02. Disponivel em http://www.fsis.usda.gov

[25] VAN NetTen, P., VAN GAAL, B.; MOssel, D.A.A. Selection, differentiation and counting haemolytic Listeria spp on PALCAM medium. Lett. Appl. Microbiol., v. 12, n. 1, p. 20-22, 1991.

[26] VAN NETTEN, P.; PERALES, I. VAN DE MOOSDIJK, A.; CURTIS, G.D.W.; MOSSEL, D.A.A. Liquid and solid selective differential media for the detection and enumeration of Listeria monocytogenes and other Listeria species. Int. J. Food Microbiol., v. 8, p. 299-316, 1989.

[27] WANG, G.-H.; YAN, K.-T.; FENG, X.-M.; CHEN, S.-M.; LUI, A.-P.; KOKUBO, Y. Isolation and identification of Listeria monocytogenes from retail meats in Beijing. J. Food Prot., v. 55, n. 1, p. 56-58, 1992.

[28] WARBURTON, D.W.; FARBER, J.M.; POWELL, C.; TIWARI, N.P.; READ, S.; PLANTE, R.; BABIUK, T.; LAFFEY, P.; KAURI, T.; MAYERS. P.; CHAMPAGNE, M.-J.; HUNT, T.; LACASSE, P.; VIET, K.; SMANDO, R.; COATES, F. Comparison of methods for optimum detection of stressed and low levels of Listeria monocytogenes. Food Microbiol., v. 9, n. 2, p. 127-145, 1992.

[29] WEDERQUisT, H.J.; SOFOS, J.N.; SCHMIDT, G.R. Culture media comparison for the enumeration of Listeria monocytogenes in refrigerated vaccum packaged turkey bologna made without chemical additives. Lebbensm.Wiss. Technol., v. 28, n. 5, p. 455-461, 1995.

\section{6 - AGRADECIMENTOS}

FAPESP (processo 97/01697-0) pelo financiamento do projeto; CNPq e CAPES pela bolsa de mestrado concedida a D. A. Rodrigues. 